\title{
PREPARATION AND CHARACTERIZATION OF ENTERIC-COATED DELAYED-RELEASE MICROSPHERE OF PHYTOSOME LOADING ALLICIN-RICH EXTRACT
}

\author{
NINING NINING*, YUDI SRIFIANA, ELY MALINDA FADLIANTY
}

Faculty of Pharmacy and Science, Universitas Muhammadiyah Prof. DR. HAMKA, Jakarta, Indonesia 13460

Email: nining@uhamka.ac.id

Received: 30 Sep 2020, Revised and Accepted: 20 Oct 2020

\begin{abstract}
Objective: Allicin, a natural organosulfur compound, is the main garlic ingredient, which has extensive pharmacological activities. Its unstable under acidic conditions due to alliinase's inactivation causes the need for preparations that delayed-release in the stomach to maximize allicin absorption. This study aimed to prepare and characterize the enteric-coated microsphere of phytosome loading allicin-rich extract to protect it from gastric acid.

Methods: The allicin-rich extract phytosome (ArE-Ps) was prepared and evaluated for characteristics. Microsphere was made in three formulas with different molar ratios of ArE-Ps and Eudragit L30D-55 (1:1; 1:1.5 and 1:2) by spray dry. The three microspheres compared to particle size, entrapment efficiency, and dissolution test in acid and $7.4 \mathrm{pH}$ medium.

Results: Optimized ArE-Ps has a size of $251.6 \mathrm{~nm}$, polydispersity index 0.466, zeta potential 34.11, entrapment efficiency of $62.62 \%$, and specific gravity of $1,005 \mathrm{~g} / \mathrm{ml}$. The surface topography of the three formulas shows an almost spherical shape with concave surfaces. The particle size of the microsphere ranges from $215 \pm 6.27 \mathrm{~nm}$ to $548.8 \pm 10.15 \mathrm{~nm}$. Entrapment efficiency increases with an increasing number of polymers with a maximum value of $65.44 \%$ at F3. The results dissolution test in vitro showed no drug release in acidic medium, and drug release occurred at a 7.4 $\mathrm{pH}$ medium. Drug release of three microsphere formulations followed the Korsmeyer-Peppas model with a $\mathrm{k}$ value of $12.7088 \pm 0.1769$; $17.9322 \pm 1.5621$; and $12.958 \pm 1.2677$; respectively.
\end{abstract}

Conclusion: Based on these results, the polymer's increase in three microsphere formulations can affect characteristics and retain drug release under acidic conditions.

Keywords: Enteric-coated, Delayed-release, Phytosome, Allicin-rich extract, Characterization

(C) 2021 The Authors. Published by Innovare Academic Sciences Pvt Ltd. This is an open access article under the CC BY license (https://creativecommons.org/licenses/by/4.0/) DOI: https://dx.doi.org/10.22159/ijap.2021.v13s3.15 Journal homepage: https://innovareacademics.in/journals/index.php/ijap

\section{INTRODUCTION}

Garlic (Allium sativum L.) is a bulbous plant that is easy to grow at temperatures and tropical conditions globally, including in Indonesia. Generally, garlic is used as a flavoring agent and seasonings [1]. This plant has many organosulfur compounds such as allicin, volatile compounds [2]. That reported having extensive pharmacological activities [3] such as antimicrobial [4], antihypertensive, nephroprotective, cardioprotective, antioxidant [5], anti-carcinogenic, antidiabetic, and cytochrome activity [2]. Allicin is known to be unstable and results from the action of the alliinase enzyme in alliin. Formulations containing allicin are complicated because of their instability. Conventional formulations to form allicin in vivo also have a big challenge because alliinase is destroyed by gastric acid [6].

One of the new vesicular complexes is a phytosome made from the encapsulation of phospholipid and extracts into phytoconstituents to improve bioavailability and enhance therapeutic benefits in oral and topical use. Phytosome technology is considered a suitable method for obtaining a better pharmacodynamic and pharmacokinetic profile for active constituents in extracts because the structure of the vesicles protects the herbs from being damaged in an acidic environment. Increased penetration into the biomembrane can be achieved with lipid-containing vesicle complexes [7]. The research conducted by Almajdoub shows that the phosphatidylcholine that forms the phytosome experiences instability in gastric fluid $\mathrm{pH}$ simulation [8]. Another study stated that the enzyme alliinase in garlic extract, which converts alliin compounds into allicin, deactivates at the $\mathrm{pH}$ of gastric acid. It causes the reduction of allicin compounds to $99 \%$ in the product [3]. Based on this, the phytosomes system was made into an enteric-coated preparation, Eudragit L30 D55. Enteric-coated preparations prevent the drug's release in the stomach and release at a more suitable place, the intestine $[9,10]$.

Polymeric Eudragit is a series of acrylic and methacrylate polymers available in various forms of ions. Eudragit L30D-55, with a molecular weight of $320,000 \mathrm{~g} / \mathrm{mol}$ [11], is an anionic copolymer containing free carboxyl groups and esters in a ratio of $1: 1$. The carboxyl group ionized in an aqueous medium at a $\mathrm{pH}$ of 5.5 and above makes the polymer resistant to the stomach's acidic environment but dissolves at intestinal pH [12]. Spray dryer performed enteric coating-this method is widely used to make microparticles, such as microspheres, with polymers containing hydrophilic, lipophilic, and macromolecular drugs [13]. The main advantages are that the process is only one step, easy to control and improve, and possibly free from organic solvents [13]. This study expected that the formed microparticles could be protected from the acidic environment and released in the intestinal environment.

The concentration of enteric coating polymers influences microparticles characteristics and their drug release in the gastrointestinal tract. A study conducted by Pyar and Peh in drug release tests in vitro showed that the concentration of L30D-55 Eudragit above $7.5 \%$ could hold active substances in the stomach environment [14]. The research was carried out on increased Eudragit L30D-55 as an enteric-coated polymer on characterizing the microsphere ArE-Ps to protect it from gastric acid.

\section{MATERIALS AND METHODS}

\section{Materials}

The materials used include an allicin-rich extract (Lansida), soy lecithin (Lansida), S-allyl 2-propane-1-sulfinothioate (Sigma Aldrich), Eudragit L30D-55 (Evonik). All other reagents used analytical grade.

\section{Methods}

\section{Preparation of phytosome}

A-4.5 of ArE and soy lecithin weighed, respectively. Then soy lecithin diluted with dichloromethane, while ArE diluted with $96 \%$ ethanol. Both solutions were mixed in a round-bottom flask. The solvent 
evaporated using a rotary evaporator (EYELA) at $30{ }^{\circ} \mathrm{C}$ with 125 $\mathrm{rpm}$. Then, a thin layer formed stored in a refrigerator for up to $24 \mathrm{~h}$ at $7{ }^{\circ} \mathrm{C}$ and hydrated with a phosphate buffer solution $\mathrm{pH}$ 5.5. Then, suspension sonicated for $60 \mathrm{~min}$.

\section{Evaluation of phytosome}

Phytosome evaluated to characterize the vesicle produced. Evaluations include entrapment efficiency, particle morphology, particle size, index polydispersity, potential zeta, and specific gravity.

\section{Preparation of phytosome-loaded microsphere}

Phytosome-loaded microsphere formulations seen in table 1 . The polymer amount is proportional to the weight of solid phytosome in 1:1; 1:1.5; and 1:2 for F1, F2, and F3, respectively. Eudragit L30D-55 was mixing with triethyl citrate and aqua dest to make a polymer solution. The dispersion of polymer and phytosome suspension dried with $150{ }^{\circ} \mathrm{C}$ as inlet temperature and $70{ }^{\circ} \mathrm{C}$ as outlet temperatures to obtain microsphere by spray dryer (BUCHI 190).

Table 1: Formula of ArE-Ps microsphere

\begin{tabular}{llll}
\hline Materials (Units) & \multicolumn{3}{l}{ Concentration } \\
\cline { 2 - 4 } & F1 & F2 & F3 \\
\hline Phytosome (\%) & 50 & 50 & 50 \\
Eudragit L30 D55 (\%) & 15 & 22.5 & 30 \\
Triethyl citrate (\%) & 0.9 & 1.125 & 1.35 \\
Aqua dest (ml) & ad 100 & ad 100 & ad 100 \\
\hline
\end{tabular}

\section{Entrapment efficiency determination}

The entrapment efficiency determined by $200 \mathrm{mg}$ microcapsule dissolved in phosphate buffer $\mathrm{pH} 7.4$, then centrifuged at 10,000 rpm for $10 \mathrm{~min}$. A-1 ml supernatant taken to measure allicin levels, which are not absorbed in the phytosome vesicles. Furthermore, the volume is sufficient with a mixed solvent phosphate $\mathrm{pH} 6.8$ and $95 \%$ ethanol (2:8), until $10 \mathrm{ml}$. A- $0.5 \mathrm{ml}$ is taken and diluted into a $10 \mathrm{ml}$ volumetric flask, and absorbance is measured using a UV-Vis spectrophotometer (1601-SHIMADZU). Measurement of absorbedallicin in the phytosome, centrifuge precipitate diluted $0.5 \mathrm{ml}$ dichloromethane, and vortexed. Then, it is diluted in a $10 \mathrm{ml}$ volumetric flask, and the absorbance is measured. The percentage of absorbed-allicin determined with the formula, $\% E E=\left(M_{1}\right.$ $\left.M_{2}\right) / M_{1} \times 100$, where $M_{1}$ is the total allicin in the microcapsule, and $M_{2}$ is allicin concentration in supernatant.

\section{Morphology of microspheres}

The morphology of microspheres evaluated using scanning electron microscopy (SEM JEOL JSM-6510LA). The microsphere is attached to the holder then inserted into a vacuum evaporator. At a specific vacuum level, the holder is incandescent so that gold vapor will coat the material attached to the holder. The holder is then inserted into the SEM device and then examined.

\section{Particle size distribution}

The particle size distribution and zeta potential were measured using a particle size analyzer (Delsa Max Pro). Some $200 \mathrm{mg}$ of microcapsules dispersed in aqua proinjection in a ratio of $1: 19$. Then it is directly inserted into a particle size analyzer, and the particle size distribution curve is determined. Zeta potential and polydispersity index measurements were also performed.

\section{In vitro drug release studies}

The procedure on this study refers to Anwar et al. [15]. The allicin releases from microcapsule carried out in two types of mediums, hydrochloric acid pH 1.2 and phosphate buffer $\mathrm{pH}$ 7.4. Drug release testing was carried out on a glass beaker placed on a magnetic stirrer at $37 \pm 0.5{ }^{\circ} \mathrm{C}$ and $100 \mathrm{rpm}$; the medium used was $100 \mathrm{ml}$. Some microcapsules are inserted into the cellophane membrane and dipped in the dissolution medium. The liquid sample is taken as much as 10 $\mathrm{ml}$ at a particular minute. On the acidic medium, samplings carried out at minutes of $5,10,15,30,45,60,90,120,180,240,300,360$, and 420 . While on the pH 7.4 medium, samplings carried out at minutes of 5,10 , $15,30,45,60,90,120$, and 180 . Every $10 \mathrm{ml}$ sample liquid was taken, then $10 \mathrm{ml}$ of the medium solution was added to the dissolution flask, in triplicate. Then allicin levels were determined by UV-Vis spectrophotometer.

\section{Release kinetic models [16, 17]}

The mechanism of releasing allicin from three microspheres studied from the calculation with four different kinetic models was performed based on experimental data. Model 1 given by the RitgerPeppas and Korsmeyer Peppas equations, $\mathrm{f}_{1}=\mathrm{M}_{\mathrm{i}} / \mathrm{M}_{\infty}=\mathrm{K}$. $\mathrm{t}^{\mathrm{n}}$, where $\mathrm{f}_{1}$ is the amount of drug released, $M_{\infty}$ and $M_{i}$ is the amount of drug at the equilibrium state and over time $\mathrm{t}$, respectively; $\mathrm{K}$ is the constant of incorporation of structural modifications and geometrical characteristics of the system, and $\mathrm{n}$ is the exponent of release in the function of time t. When $n=0.43$, the drug release mechanism is the Fickian diffusion for the spherical delivery system. When $n=0.85$, the drug release mechanism is ultimately Case II transport. When $0.43>n>0.85$, anomalous transport was observed.

Model 2 is the Higuchi model. Although this model is frequently used to describe the drug transport mechanism of thin-film hydrogels, this model can also be used to analyze spherical hydrogel systems' transport mechanism - the equation, $\mathrm{f}_{1}=\mathrm{K}_{\mathrm{H}} \sqrt{\mathrm{t}}$, where $\mathrm{K}_{\mathrm{H}}$ is the release constant of Higuchi.

Model 3 is based on the zero-order drug delivery and expressed when $\mathrm{n}=1$ in Korsmeyer Peppas equation, $\mathrm{f}_{\mathrm{i}}=\mathrm{K}_{0} . t$, where $\mathrm{f}_{\mathrm{i}}=1-\left(\mathrm{W}_{\mathrm{i}} / \mathrm{W}_{0}\right)$ represents the fraction of active agent dissolved during the time $t$, and $\mathrm{K}_{0}$ is a constant of the apparent velocity of dissolution.

Model 4 represents first-order drug delivery and is expressed by the following equation, $\log Q_{1}=\log Q_{0}+\left(k_{1} . t / 2.303\right)$, where $Q_{1}$ is the amount of active agent released on time $t, Q_{0}$ is the initial amount of drug dissolved, and $\mathrm{K}_{1}$ is the first-order constant.

\section{Statistical analysis}

One-way Analysis of Variance (ANOVA) analyzed dissolution rate data with a confidence level of $95 \%(\alpha=0.05)$ to determine any differences in all formulas. Then, further test by Tukey HSD to determine significant differences in each formula.

\section{RESULTS AND DISCUSSION}

Table 2: Characteristics of ArE

\begin{tabular}{lll}
\hline Parameters (Units) & Result & Requirement \\
\hline Organoleptic & & \\
Form & Sticky & Sticky \\
Odor & Strong aromatic & Strong aromatic \\
Color & Brown & Brown \\
Taste & Bitter & Bitter \\
Water content (\%) & 1.21 & No more 12 \\
Total ash content (\%) & 3.43 & No more 2.7 \\
Acid-insoluble ash (\%) & 0.15 & No more 0.7 \\
\hline
\end{tabular}

Before use, ArE preformulated by various evaluations parameter presented in table 2. Organoleptic observation gives the physical form, color, smell, and taste of the extract. The water content and acid-insoluble ash of ArE was a meet requirement. While total ash content showed exceed form requirement. These results are the same as those obtained by Phan et al. [18], the total-ash value of 3.5$3.7 \%$ by gravimetric method, wherein mineral content associated with raw garlic condition used and planting grounds. Allicin (S-Allyl2-propene-1-sulfinothioate) is a volatile compound; allicin in extracts identified using gas chromatography with a mass spectrometer detector. The chromatogram (fig. 1) showed a similar peak between extract sample and standard allicin at a retention time of $7.72 \mathrm{~min}$. Allicin calibration curve equation is $\mathrm{y}=-0.0497+0.0520 \mathrm{x}$ with a correlation coefficient (R) of 0.9981 by spectrophotometric. Based on the curve, allicin concentration in extract was $11.29 \%$; it becomes a reference in preparing phytosome. 




Fig. 1: Chromatogram of S-Allyl-2-propene-1-sulfinothioate from ArE (a) and standard allicin (b)



Fig. 2: Morphology of ArE-Ps using TEM

The optimal conditions for preparing phytosomes are using $4.5 \mathrm{~g}$ ArE, 4.5 g soy lecithin rotated with a temperature of $30{ }^{\circ} \mathrm{C}$ and speed of $125 \mathrm{rpm}$. Soy lecithin is a phospholipids source with a higher proportion of around $76 \%$ phosphatidylcholine with a high content of polyunsaturated fatty acids, such as linoleic acid, about $70 \%$, linolenic acid and oleic acid [19]. Based on the TEM result in fig. 2, phytosome vesicles have a round shape with varying sizes. This shape is formed after the choline head of the molecule binds with phytoconstituents, and the fat-soluble part of phosphatidylcholine then encloses the material bound to choline. It produces small cells such as micelles in the water environment. The vesicle size from the TEM is not far from the PSA, around $200 \mathrm{~nm}$.
Table 3: Characterization of ArE-Ps optimum formulation

\begin{tabular}{ll}
\hline Parameters (Units) & Result \\
\hline Entrapment efficiency (\%) & 62.62 \\
Dmean $_{\text {(nm) }}$ & 251.605 \\
Polydispersity index (PDI) & 0.466 \\
Zeta potential & 34.1088 \\
Specific density $(\mathrm{g} / \mathrm{ml})$ & 1.0051 \\
\hline
\end{tabular}

Microsphere, made in three formulas with different molar ratios of ArE-Ps and Eudragit L30D-55 (1:1; 1:1.5 and 1:2) by spray dry, produces different sizes. Based on the result, the microsphere size was $548.8 \mathrm{~nm}, 215.0 \mathrm{~nm}$, and $335.3 \mathrm{~nm}$, respectively, for F1, F2, and F3. Particle size from spray drying can be influenced by the size of the nozzle, viscosity of the polymer solution, dispersion of the active substance in the polymer solution, and surface tension [20]. There are significant differences in the three formulas in the particle size values from the results of data analysis with differences in the concentration of Eudragit L30D-55 polymers. The michrosphere of $\mathrm{F} 1$ has zeta potential below- $30 \mathrm{mV}$ to allow agglomeration between particles to make the particle size larger. Nanoparticles with zeta potential below $-30 \mathrm{mV}$ and above $+30 \mathrm{mV}$ have good suspension stability because the surface charge prevents aggregation between particles [15]. Zeta potential values F1, F2, and F3 respectively; $28.88 \pm 0.81 ;-32.15 \pm 1.29$; and $-30.20 \pm 0.61$. The results show that only F2 and F3 can prevent aggregation between particles because they have a negative potential zeta value below- $30 \mathrm{mV}$.
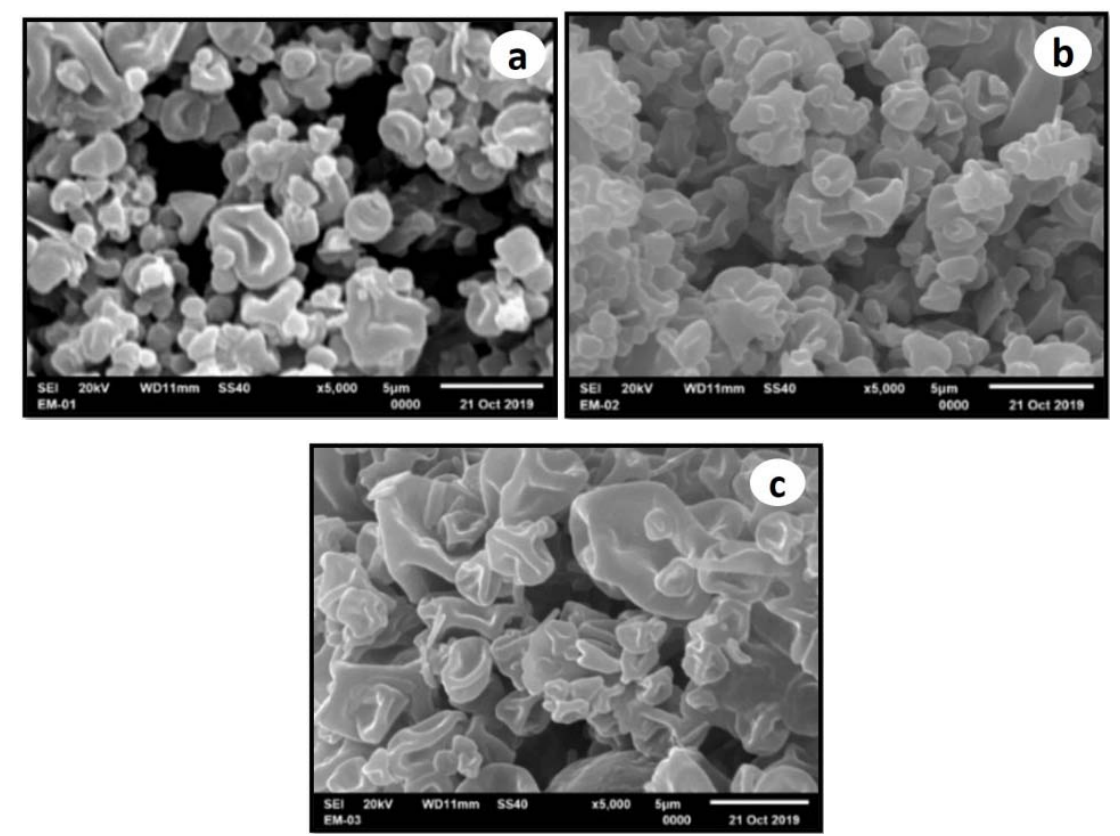

Fig. 3: Morphological structure of 5000x magnification microcapsules (a) ratio 1:1 (b) ratio 1:1.5 (c) ratio 1:2 
Table 4: Microsphere evaluation results

\begin{tabular}{llll}
\hline $\begin{array}{l}\text { Ratio } \\
\text { (ArE-Ps: Eud) }\end{array}$ & Result & & \\
\cline { 2 - 4 } $1: 1$ & Entrapment efficiency (\%) & D & \\
\hline $1: 1,5$ & 58,93 & $548,8 \pm 10,15$ & Zeta potential \\
$1: 2$ & 62,31 & $215,0 \pm 6,27$ & $-28,88 \pm 0,81$ \\
\hline
\end{tabular}

The morphological structure presented in fig. 3, microsphere appears as an irregular shape with many deflections, no uniform sizes, and no porous surface. Nijdam and Langrish estimate that giving a high temperature causes water to evaporate faster and gives a non-uniform structure [21]. During the high-temperature drying process, the evaporation of water solvent molecules in the droplet occurs so rapidly that it causes "emptiness" in the droplet whose surface has formed a film layer and results in a form of rounded particles that deflate [22].

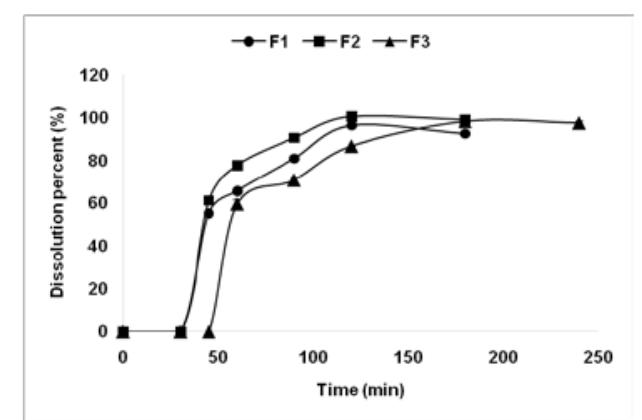

Fig. 4: Percent dissolution of the microsphere in a buffer medium $\mathrm{pH}$ of 7.4
The in vitro dissolution profile of microsphere from all formulations in acidic medium ( $\mathrm{pH} \mathrm{1.2)} \mathrm{and} \mathrm{phosphate} \mathrm{buffer} \mathrm{medium} \mathrm{(} \mathrm{pH}$ 7.4) shown in fig. 4. In acidic medium for $480 \mathrm{~min}$, all formulation shows no allicin release, marked with the absence of absorbance in the sample taken. It proves that Eudragit from all three formulations can retain the release of allicin in an acidic medium. The microsphere of $\mathrm{F} 1$ and $\mathrm{F} 2$ in alkaline $\mathrm{pH} 7.4$, began to release allicin at $45 \mathrm{~min}$ by $55.23 \pm 0.00 \%$ and $61.26 \pm 0,66 \%$. At the same time, F3 microcapsules release allicin at $60 \mathrm{~min}$ by $59.50 \pm 1.85 \%$. The F3 microsphere retains allicin release longer because it contains more polymers than F1 and F2. Release of allicin caused by salt formation between the polymers Eudragit with alkali at $\mathrm{pH} 7.4$ so the polymer layer can dissolve. The microsphere of F1 and F2 dissolve entirely in the $120 \mathrm{~min}$, while $\mathrm{F} 3$ in the $180 \mathrm{~min}$. The different rates of dissolving active substances released from the microsphere influenced by the thickness of the coating wall and surface pores. Fewer constituent polymers and thinner coating walls allow active substances to release faster in phosphate buffer $\mathrm{pH}$ 7.4.

Furthermore, dissolution percent of microsphere from all formulation analyzed by fitting them to four model drug releases kinetics equations such as kinetics of zero-order, first-order, Higuchi and Korsmeyer-Peppas. From each equation, we get the drug release constant (k), correlation coefficient ( $\mathrm{r}$ ), and exponent dissolution of Peppas (n).

Table 5: Kinetics of allicin release in microsphere

\begin{tabular}{lllll}
\hline Model & Formulation & Parameter & & K \\
\cline { 3 - 5 } & & $\mathbf{R}^{2}$ & 12.60 & 0.40 \\
\hline Korsmeyer-Peppas & F1 & 0.8805 & 17.93 & 0.35 \\
& F2 & 0.8461 & 12.96 & 0.38 \\
\hline
\end{tabular}
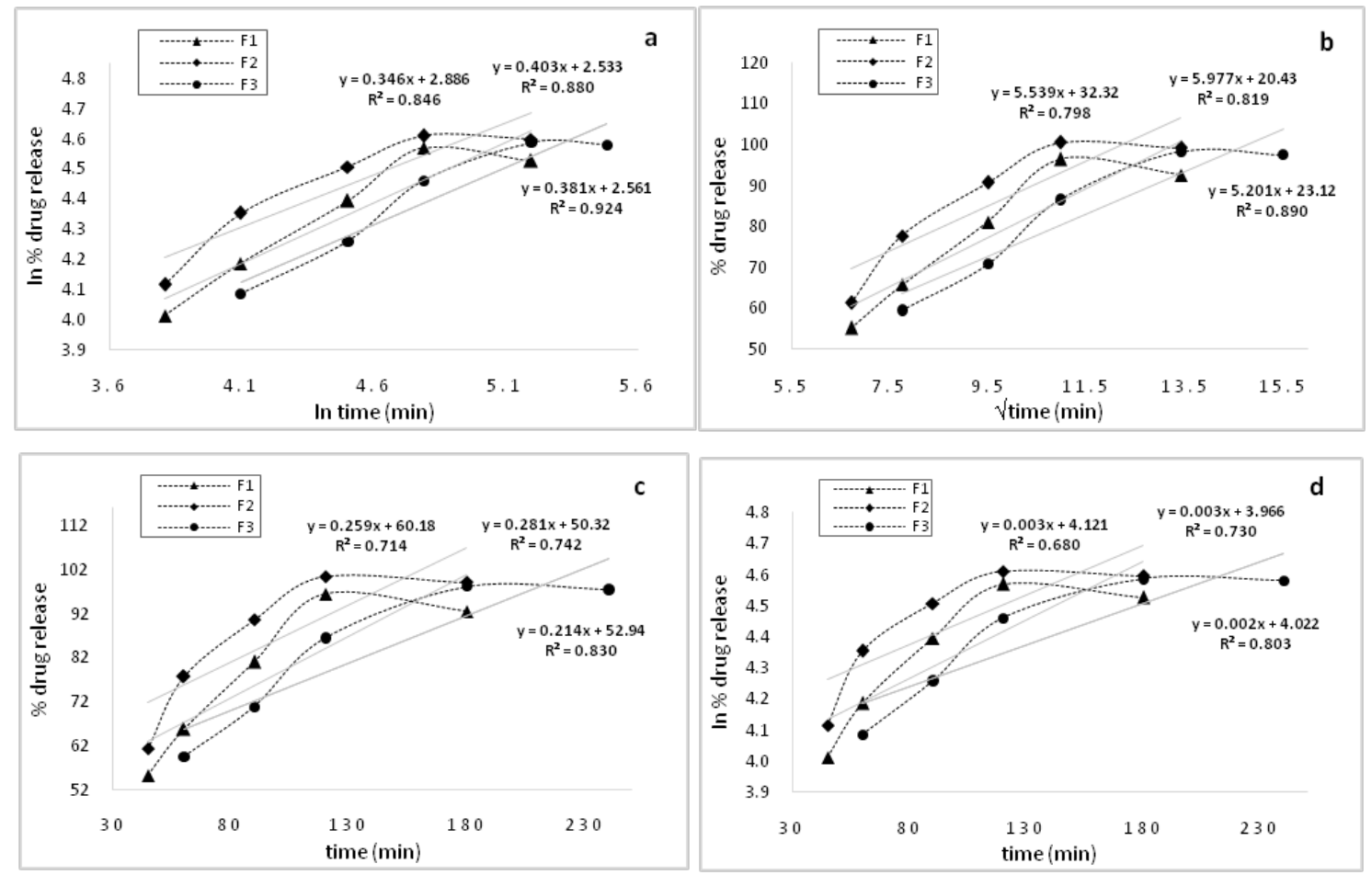

Fig. 5: Drug release kinetics plots for all formulations (a) Korsmeyer-Peppas (b) Higuchi (c) Zero-order (d) First-order 
Based on table 5, allicin release from the microsphere follows the Korsmeyer-Peppas kinetics. The Korsmeyer-Peppas equation explains the mechanism of drug release from preparations based on the Fickian model mechanism is the same as Higuchi. In the Korsmeyer-Peppas equation, the release mechanism depends on the value ' $\mathrm{n}$ ' when $\mathrm{n}=0.43$; the Fickian diffusion governs the drug release mechanism when $0.43<\mathrm{n}<0.85$ it is anomalous (non-Fickian) transport, and when $n=0.85$ it is case II transport [16]. The $n$ values of all formulation $<0.45$ indicate the release mechanism follows the Fickian model. According to Fickian, the dissolution rate of solid form is determined by the dissolution rate of a thin layer of a solution formed around the solid. The drug dissolved in a saturated solution diffuses into the solvent from high concentration to an area of low drug concentration.

Data on the dissolution rate analyzed statistically to see the differences between the three formulas. The normality test resulted in sig values of $0.247 ; 0.429$; dan 0.075 ( $\operatorname{sig}>0.05$ ); then, the homogeneity test resulted in sig values of 0.056 (sig>0.05); it concluded the data typically distributed and homogeneous. Furthermore, a one-way ANOVA test resulted in sig values of 0.002 (sig<0.05); it concluded a significant difference in the dissolution rate of microsphere between all formulations.

Based on these results, the polymer's increase in three microsphere formulations can affect characteristics and retain drug release under acidic conditions. The three formulations follow Korsmeyer-Peppas kinetics release with $\mathrm{k}$ values $12.71 \pm 0.18$; $17.93 \pm 1.56$; and $12.96 \pm 1.27$, for F1, F2, and F3, respectively.

\section{FUNDING}

Nil

\section{AUTHORS CONTRIBUTIONS}

All the authors contributed equally.

\section{CONFLICT OF INTERESTS}

Declared none

\section{REFERENCES}

1. Morales Gonzalez JA, Madrigal Bujaidar E, Sanchez Gutierrez M, Izquierdo Vega JA, Carmen Valadez Vega M Del, Alvarez Gonzalez I, et al. Garlic (Allium sativum L.): a brief review of its antigenotoxic effects. Foods 2019;8:1-17.

2. Sharifi Rad J, Silva NCC, Jantwal A, Bhatt ID, Sharopov F, Cho $\mathrm{WC}$, et al. Therapeutic potential of allicin-rich garlic preparations: emphasis on clinical evidence toward upcoming drugs formulation. Appl Sci 2019;9:1-16.

3. Khorshed Alam M, Obydul Hoq M, Shahab Uddin M. Medicinal plant allium sativum. J Med Plants Stud 2016;4:72-9.

4. Viswanathan V, Phadatare A, Mukne A. Antimycobacterial and antibacterial activity of allium sativum bulbs. Indian J Pharm Sci 2014;76:256-61.

5. Garcia Trejo EMA, Arellano Buendia AS, Arguello Garcia R, Loredo Mendoza ML, Garcia Arroyo FE, Arellano Mendoza MG, et al. Effects of allicin on hypertension and cardiac function in chronic kidney disease. Oxid Med Cell Longev 2016. DOI:10.1155/2016/3850402.

6. Phadatare AG, Viswanathan V, Mukne A. Novel strategies for optimized delivery of select components of allium sativum. Pharmacognosy Res 2014;6:334-40.
7. Guler E, Demir B, Guler B, Demirkol DO, Timur S. Biofu nctionalized nanomaterials for targeting cancer cells [Internet]. Nanostructures for Cancer Therapy. Elsevier Inc; 2017. p. 51-86.

8. Almajdoub SS. Polymer coating of an optimized nano lipid carrier system of harpagophytum procumbens extract for oral delivery [Master's thesis, University of the Western Cape]. Institutional Repository at the University of the Western Cape; 2017.

9. Lawson LD, Gardner CD. Composition, stability, and bioavailability of garlic products used in a clinical trial. J Agric Food Chem 2005;53:6254-61.

10. Lawson LD, Hunsaker SM. Allicin bioavailability and bioequivalence from garlic supplements and garlic foods. Nutrients 2018;10:4-6.

11. Halimi M, Alishahi M, Abbaspour MR, Ghorbanpoor M, Tabandeh MR. Efficacy of a Eudragit L30D-55-encapsulated oral vaccine containing inactivated bacteria (Lactococcusgarvieae/ Streptococcus iniae) in rainbow trout (Oncorhynchus mykiss). Fish Shellfish Immunol 2018;81:430-7.

12. Rahman MA, Ali J. Development and in vitro evaluation of enteric-coated multiparticulate system for resistant tuberculosis. Indian J Pharm Sci 2008;70:477-81.

13. Raffin RP, Jornada DS, Re MI, Pohlmann AR, Guterres SS Sodium pantoprazole-loaded enteric microparticles prepared by spray drying: effect of the scale of production and process validation. Int J Pharm 2006;324:10-8.

14. Pyar H, Peh KK. Enteric coating of granules containing the probiotic lactobacillus acidophilus. Acta Pharm 2014; 64:247-56.

15. Anwar E, Farhana N. Formulation and evaluation of phytosome-loaded maltodextrin-gum arabic microsphere system for delivery of camellia sinensis extract. J Young Pharm 2018;10:s56-62.

16. Dash S, Murthy PN, Nath L, Chowdhury P. Kinetic modeling on drug release from controlled drug delivery systems. Acta Pol Pharm Drug Res 2010;67:217-23.

17. Unagolla JM, Jayasuriya AC. Drug transport mechanisms and in vitro release kinetics of vancomycin encapsulated chitosanalginate polyelectrolyte microparticles as a controlled drug delivery system. Eur J Pharm Sci 2018;114:199-209.

18. Phan ADT, Netzel G, Chhim P, Netzel ME, Sultanbawa Y. Phytochemical characteristics and antimicrobial activity of Australian grown garlic (Allium sativum L.) cultivars. Foods 2019;8:358.

19. Saraf S, Khan J, Alexander A, Ajazuddin, Saraf S. Recent advances and future prospects of phyto-phospholipid complexation technique for improving pharmacokinetic profile of plant actives. J Controlled Release 2013;168:50-60.

20. Srifiana Y, Surini S, Yanuar A. Encapsulation of ketoprofen with coaservation and spray drying methods using pregelatinized cassava starch phtlate as a film-forming excipient. J Ilmu Kefarmasian Indones 2014;12:162-9.

21. Nijdam JJ, Langrish TAG. The effect of surface composition on the functional properties of milk powders. J Food Eng 2006;77:919-25.

22. Nining N, Suwandi SN, Wikarsa S. Rosella flower (Hibiscus sabdariffa L.) extract drying through microencapsulation of spray drying method with maltodextrin. Farmasains 2017;4:65-71. 